\title{
PEMIJATAN PADA TITIK LI-4 UNTUK MENGURANGI NYERI KANULASI AV-FISTULA PADA PASIEN HEMODIALISIS
}

\author{
Ria Desnita ${ }^{1 *}$ \\ ${ }^{1}$ Prodi S1 Keperawatan STIKes MERCUBAKTIJAYA Padang \\ Jalan Jamal Jamil Pondok Kopi Siteba Padang \\ *Email : ria.desnita18@gmail.com
}

\begin{abstract}
Massage at LI-4 point to reduce pain during AV-fistula Cannulation in hemodialysis patients. One of vascular accesses used for hemodialysis is arteriovenous fistula (AV-fistula). Cannulation of AV-fistula cause pain for patients. Based on evidence based, massage at the point of large intestinum 4 (LI-4 or huko point) is intervention than can be applied to reduce pain in AV-fistula cannulation. Implementation of evidence based nursing aimed to identify the effectiveness of massage at the LI-4 point to reduce pain during AV-fistula cannulation in hemodialysis patients. Implementation of evidence based nursing was applied in April 2017. The sample size was 14 hemodialysis patients. The result of Implementation of evidence based nursing showed that Massage at LI-4 points was effective to reduce pain at AV-fistula cannulation ( $p<0,001)$. Massage at LI-4 point can be applied by nurses as nonpharmacologic pain management interventions to reduce pain in $A V$-fistula cannulation at hemodialysis patients.
\end{abstract}

Keywords: Pain, AV-fistula cannulation, hemodialysis, massage at LI-4 point

\begin{abstract}
Abstrak
Salah satu akses vaskuler yang digunakan untuk hemodialisis adalah arterivenous fistula (AVfistula). Kanulasi AV-fistula menimbulkan masalah nyeri pada pasien. Berdasarkan bukti ilmiah, pemijatan pada titik large intestinum 4 (LI-4 atau huko point) adalah intervensi yang dapat diterapkan untuk mengurangi nyeri kanulasi AV-fistula. Tujuan penerapan EBN ini adalah mengidentifikasi efektifitas pemijatan pada titik LI-4 pada penurunan nyeri saat kanulasi AVfistula pada pasien hemodialisis. Penerapan EBN dilakukan pada bulan April 2017. Jumlah sampel 14 orang pasien hemodialisis. Hasil penerapan EBN menunjukkan pemijatan titik LI-4 efektif dalam menurunkan nyeri kanulasi AV-fistula $(\mathrm{p}<0,001)$. Pemijatan pada titik LI-4 dapat diaplikasikan perawat sebagai intervensi manajemen nyeri non farmakologis untuk mengurangi nyeri kanulasi AV-fistula pada pasien hemodialisis.
\end{abstract}

Kata Kunci: nyeri, kanulasi AV-fistula, hemodialisis, pemijatan titik LI-4

\section{Latar Belakang}

Gagal ginjal kronik menjadi permasalahan di bidang nefrologi dengan angka kejadian yang tinggi. Berdasarkan data dari National Kidney Foundation (2016) 10\% dari total populasi di dunia menderita penyakit gagal ginjal kronik dan jutaan orang meninggal setiap tahunnya karena akses pengobatan yang tidak memadai.
Menurut Global Burden of Disease Study (2010), gagal ginjal kronik menempati peringkat ke 27 dalam daftar penyebab total kematian di seluruh dunia pada tahun 1990 dan mengalami peningkatan menjadi peringkat 18 pada tahun 2010 (Jha et al., 2013). Hasil Riset Kesehatan Dasar (Riskesdas) tahun 2013 menunjukkan penyakit gagal ginjal kronik menempati 
urutan ke 10 penyakit terbanyak di Indonesia dengan prevalensi 0,2\% (Kementrian Kesehatan RI, 2013). Laporan studi epidemiologi klinik di Indonesia menyatakan bahwa gagal ginjal terminal sebagai akibat lanjut dari gagal ginjal kronik menempati urutan pertama dari semua penyakit ginjal (Sukandar, 2013).

Pasien gagal ginjal terminal memerlukan terapi pengganti fungsi ginjal untuk mempertahankan kelangsungan hidupnya. Salah satu terapi pengganti fungsi ginjal adalah terapi hemodialisis (Sukandar, 2013). Hemodialisis merupakan terapi yang berfungsi menggantikan fungsi ginjal untuk mengeluarkan produk sisa metabolisme dan air yang ada pada darah melalui membran semipermiabel atau dializer (Sukandar, 2013). Proses hemodialisis membutuhkan akses vaskuler untuk mengalirkan darah keluar tubuh menuju dializer dan mengalirkan darah dari dializer masuk kembali ke dalam tubuh setelah dilakukan penyaringan.

Salah satu akses vaskuler yang biasanya digunakan untuk hemodialisis adalah arterivenous fistula. Penggunaan arterivenous fistula membutuhkan insersi jarum melalui penusukan atau kanulasi pada saat akan dilakukan hemodialisis. Insersi jarum atau penusukan pada arterivenous fistula dilakukan setiap pasien akan dilakukan hemodialisis. Penusukan arterivenous menimbulkan sensasi nyeri pada pasien (Figueiredo, Viegas, Monteiro, \& Poli, 2008). Nyeri yang dirasakan pasien saat penusukan akan berbeda pada setiap pasien tergantung kepada ambang batas nyeri masing-masing individu. Hasil penelitian Kaza et al. (2014) menunjukkan bahwa nyeri saat penusukan arterivenous fistula dirasakan oleh $47 \%$ pasien yang menjalani hemodialisis. Nyeri sebagai salah satu masalah keperawatan pada saat penusukan arteriovenous fistula merupakan stimulus yang dirasakan dalam waktu cepat, tetapi bisa dirasakan sebagai suatu sensasi kesakitan yang berat bagi sebagian pasien. Nyeri yang dirasakan oleh pasien berdampak terhadap kecemasan dan ketakutan untuk menjalani hemodialisis (Figueiredo et al., 2008). Kecemasan dan ketakutan dapat menimbulkan ketidakpatuhan pasien untuk menjalani terapi hemodialisis setiap sesinya sehingga pada akhirnya dapat menyebabkan penurunan kualitas hidup pasien (Figueiredo et al., 2008)

Berdasarkan fenomena yang ditemukan penulis di ruangan hemodialisis Rumah Sakit Umum Pusat Fatmawati, nyeri saat penusukan arterivenous juga menjadi masalah yang dialami sebagian besar pasien. Sensasi nyeri yang dirasakan pasien juga bervariasi, dari nyeri ringan hingga nyeri yang berat. Pasien yang mengalami nyeri berat biasanya akan mengatakan kecemasan dan ketakutan saat akan dilakukan penusukan. Hasil pengamatan penulis terhadap penatalaksanaan nyeri saat penusukan yang dilakukan oleh perawat adalah meminta pasien untuk melakukan nafas dalam saat penusukan. Dari hasil wawancara penulis dengan kepala ruangan hemodialisis diketahui bahwa untuk penanganan nyeri saat penusukan arterivenous di ruang hemodialisis RS Fatmawati juga tidak dilakukan pemberian anastesi lokal di area penusukan. Dari hasil wawancara lebih lanjut juga diketahui bahwa intervensi yang pernah diterapkan untuk mengatasi nyeri kanulasi adalah dengan memberikan kompres es pada area penusukan, tetapi tindakan ini tidak lagi dilaksanakan karena kesulitan untuk menyediakan es.

Berdasarkan hasil penelusuran evidence based practice, salah satu intervensi yang dapat diterapkan perawat untuk mengatasi masalah nyeri penusukan arteriovenous adalah dengan melakukan pemijatan pada 
titik large intestinum 4 (LI-4 atau huko point) (Fareed, El-Hay, \& El-Shikh, 2014). Titik LI-4 adalah titik yang terletak diantara ibu jari dengan telunjuk (Fareed et al., 2014). Stimulasi pada titik LI-4 menyebabkan perangsangan pada inhibitory neuron untuk mencegah projection neuron mengirim sinyal dan rangsangan nyeri ke otak, sehingga gerbang tertutup dan persepsi nyeri akan berkurang (Mirtajadini, Kalroozi, \& Pishgooie, 2016). Pemijatan pada titik LI4 bersifat lokal sehingga tidak akan menimbulkan efek samping pada sistem tubuh lain.

Beberapa hasil penelitian telah menunjukkan efektifitas pemijatan pada titik LI-4 terhadap nyeri penusukan arteriovenous fistula pada pasien hemodialisis. Hasil penelitian Mirtajadini et al. (2016) menyebutkan bahwa terdapat penurunan skor nyeri pada pasien yang mendapatkan terapi pijat shiatsu pada titik LI-4 sebesar 2,22, hasil analisis lebih lanjut membuktikan terdapat pengaruh pijat shiatsu pada titik LI-4 terhadap penurunan skor nyeri penusukan arteriovenous pada pasien hemodialisis. Hasil penelitian (Ziba, Soltanpoor, \& Mohammadi, 2013) juga menunjukkan bahwa pemijatan dengan es dan tanpa es pada hoku point (LI-4) berpengaruh terhadap penurunan skala nyeri saat penusukan arteriovenous fistula pada pasien yang menjalani hemodialisis $(\mathrm{p}<0,001)$.

Pemijatan pada titik LI-4 merupakan metode non farmakologis sederhana dan dapat digunakan oleh perawat untuk mengatasi nyeri pada pasien yang akan dilakukan penusukan arteriovenous fistula (Fareed et al., 2014).

\section{Penerapan EBN}

Pelaksanaan EBN berupa pemijatan pada titik LI-4 dilakukan untuk mengurangi nyeri saat kanulasi arteriovenous fistula.
Penerapan EBN dimulai pada 13 maret 2017 sampai 1 April 2017.

Penerapan EBN dilakukan dengan melibatkan perawat di ruang hemodialisis RSUP Fatmawati. Minggu pertama pelaksanaan diawali dengan mengidentifikasi pasien sesuai kriteria inklusi dan eksklusi yang ditetapkan. Pelaksanaan EBN dilakukan pada 14 orang pasien. Pasien dikelompokkan menjadi kelompok intervensi dan kelompok kontrol. Kelompok intervensi adalah kelompok yang mendapatkan pemijatan pada titik LI-4 sebelum kanulasi arteriovenous fistula. Kelompok kontrol adalah kelompok yang tidak mendapatkan intervensi pemijatan pada titik LI-4 sebelum kanulasi arteriovenous fistula, kelompok ini hanya mendapatkan terapi nafas dalam.

\section{Hasil dan Pembahasan}

Gambaran karakteristik pasien dalam pelaksanaan EBN dapat dilihat pada tabel 1.1 berikut.

\begin{tabular}{|c|c|c|c|c|c|}
\hline \multicolumn{6}{|c|}{ 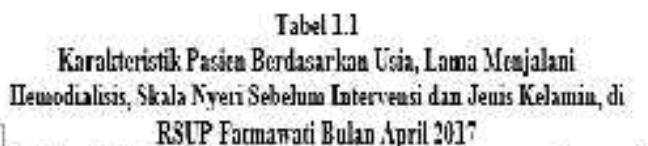 } \\
\hline Kankteristik Pasifn & " & Mem I SD & $\begin{array}{l}\text { Min- } \\
\text { Maks }\end{array}$ & $f$ & 3 \\
\hline \multicolumn{6}{|l|}{ Usta } \\
\hline Ktiaquishodud & 7 & $6.57=9.99$ & $31-73$ & & \\
\hline Kecrapos inteniesi & i & $4 y, ": 11,0$ & $9-5 b$ & & \\
\hline \multicolumn{6}{|l|}{ Jenis Kielnmin } \\
\hline Beicrpoitiend & 7 & & & & \\
\hline Indil biti & & & & 3 & 129 \\
\hline Petenyles. & & & & 4 & 37,1 \\
\hline Kecripas intenechi & i & & & & \\
\hline Taliviliki & & & & 4 & $i n, 1$ \\
\hline Percemprar & & & & 3 & 129 \\
\hline \multicolumn{6}{|l|}{ Lama Mcnjalıni HID } \\
\hline Beviopis haded & $?$ & $5: .3=12$ & $11-513$ & & \\
\hline Ketcropos interie:hi & : & b., $14: 10,4$ & $9-4]$ & & \\
\hline \multicolumn{6}{|l|}{ Skxah Sytri Belutum } \\
\hline \multicolumn{6}{|l|}{ Internensi } \\
\hline Beiorpoiz tweind & $?$ & $1,5,=1,15$ & 36 & & \\
\hline Beiropis ulatitea & $?$ & $3,57=0,79$ & $5-?$ & & \\
\hline
\end{tabular}

Berdasarkan tabel 1.1 terlihat bahwa usia pada kelompok intervensi cendrung lebih muda dari pada kelompok kontrol. 
Distribusi jenis kelamin terlihat jumlah presentasi pasien perempuan dan laki-laki hampir sama pada kelompok intervensi dan kelompok kontrol. Dilihat dari lama hemodialisis terlihat bahwa rerata lama menjalani hemodialisis lebih lama pada kelompok kontrol dibandingkan kelompok intervensi. Berdasakan nyeri sebelum diberikan intervensi, rerata skala nyeri pada kelompok intervensi lebih tinggi dibandingkan kelompok kontrol.

Hasil analisis pengaruh pemijatan pada titik LI-4 terhadap nyeri penusukan AVfistula dapat dilihat pada tabel 1.2 berikut.

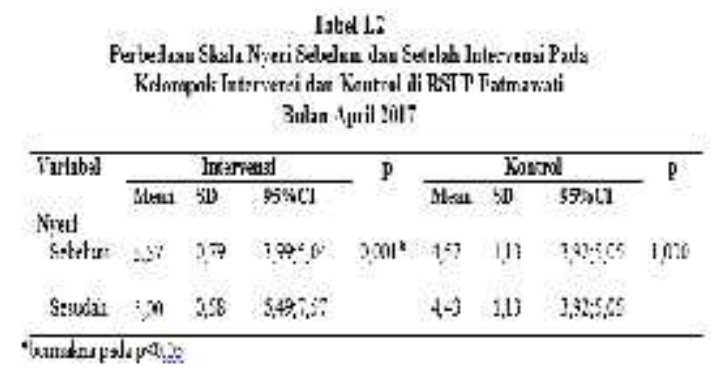

Berdasarkan tabel 1.2 di atas, terlihat penurunan rerata skala nyeri sebelum pemijatan titik LI-4 dengan skala nyeri setelah pemijatan pada kelompok intervensi artinya terdapat pengaruh pemijatan titik LI-4 terhadap skala nyeri penusukan AV-fistula pada kelompok intervensi $(p=0,001)$. Pada kelompok kontrol terlihat tidak terdapat perbedaan skala nyeri sebelum dan sesudah diberikan intervensi $(\mathrm{p}=1,000)$.

Gambaran pengaruh karakteristik pasien yang meliputi usia, lama hemodialisis serta jenis kelamin terhadap nyeri penusukan AV-fistula dapat dilihat pada tabel 1.3 berikut.

Tabe] 1.3

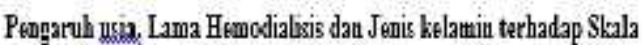

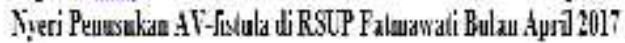

\begin{tabular}{|c|c|}
\hline Variabel & Nilaip \\
\hline Usa & 9061 \\
\hline Iamibenowalis & $93 \hat{y}$ \\
\hline Jeris Kelamin & 3477 \\
\hline
\end{tabular}

Berdasarkan tabel 1.3 di atas dapat disimpulkan bahwa tidak terdapat pengaruh usia, lama menjalani hemodialisis dan jenis kelamin terhadap nyeri penusukan $\mathrm{AV}$-fistula $(\mathrm{p}>0,05)$.

Nyeri saat kanulasi arteriovenous fistula termasuk di dalam kategori nyeri akut. Nyeri saat penusukan arteriovenous fistula merupakan sensasi yang tidak menyenangkan dirasakan oleh pasien dalam awitan waktu yang sangat cepat saat diberikan stimulus. Stimulus nyeri ini adalah penusukan. Penusukan dirasakan sebagai suatu sensasi nyeri yang perlu mendapatkan penanganan pada pasien hemodialisis karena ukuran jarum yang digunakan cukup besar dibandingkan penusukan saat pasang infus. Ukuran jarum saat penusukan arteriovenous fistula adalah 16 gauge. Pada pasien juga akan dilakukan 2 kali penusukan dimana penusukan pertama adalah untuk sirkulasi darah dari tubuh ke mesin dan penusukan ke dua adalah untuk sirkulasi darah dari mesin kembali ke tubuh.

Berdasarkan hasil analisis data menunjukkan efektifitas pemijatan titik LI-4 terhadap nyeri saat kanulasi arteriovenous fistula $(\mathrm{p}<0,001)$. Pada kelompok yang mendapatkan intervensi pemijatan titik LI-4 diketahui rata-rata skala nyeri sebelum intervensi adalah 5,57 dan rata-rata skala nyeri post intervensi adalah 3,00. Dari skala tersebut menunjukkan bahwa di saat sebelum intervensi nyeri yang dirasakan pasien berada pada skala nyeri sedang dan pada saat setelah mendapatkan intervensi pemijatan titik LI-4 didapatkan rerata skala nyeri berada pada kategori nyeri ringan. Sedangkan pada kelompok yang tidak mendapatkan intervensi pemijatan pada titik LI-4, rata-rata skala nyeri sebelum intervensi adalah 4,57 dan skala nyeri setelah intervensi adalah 4,43. Terdapat sedikit penurunan rerata skala nyeri pada kelompok yang tidak 
mendapatkan intervensi pemijatan pada titik LI-4, tetapi secara kategori nyeri pre intervensi dan post intervensi pada kelompok ini tetap dikategorikan pada nyeri sedang.

Hasil penerapan EBN ini sejalan dengan beberapa penelitian terdahulu yang juga menunjukkan pemijatan pada titik LI-4 menurunkan skala nyeri penusukan arteriovenous fistula pada pasien yang menjalani hemodialisis. Hasil penelitian (Mirtajadini et al., 2016) menunjukkan bahwa pemijatan dengan metode shiatsu pada titik LI-4 menurunkan nyeri penusukan arteriovenous fistula $(\mathrm{p}=0,001)$, dimana rerata skala nyeri sebelum intervensi adalah 5,91 dan rerata nyeri setelah intervensi adalah 3,69. Hasil penelitian (Ziba et al., 2013) juga menunjukkan efektifitas pemijatan pada titik LI-4 pada penurunan nyeri kanulasi arteriovenous fistula pada pasien yang menjalani hemodialisis $(\mathrm{p}<0,001)$, dimana rerata nyeri sebelum intervensi adalah 6,12 dan rerata nyeri setelah intervensi adalah 3,56. Kedua hasil penelitian ini menunjukkan penurunan skala nyeri dari nyeri sedang ke nyeri ringan.

Pemijatan pada titik LI-4 merupakan salah satu penatalaksanaan nyeri secara non farmakologis yang dapat diterapkan perawat untuk mengurangi nyeri penusukan arteriovenous fistula pada pasien hemodialisis. Stimulasi pada titik LI-4 menyebabkan perangsangan pada inhibitory neuron untuk mencegah projection neuron mengirim sinyal dan rangsangan nyeri ke otak, sehingga gerbang tertutup dan persepsi nyeri akan berkurang. Proses penurunan nyeri penusukan arteriovenous fistula dengan pemberian intervensi pemijatan pada titik LI-4 sejalan dengan teori gate-control. Pemijatan pada titik LI-4 mengakibatkan pengaktifan gerbang pengendali nyeri sehingga nantinya persepsi nyeri dialihkan. Pada teori gate-control dijelaskan dimana nyeri dapat teralihkan apabila stimulus nyeri berinteraksi dengan sensasi lain, sensasi lain disini adalah sensasi pemijatan sehingga menimbulkan pemblokiran transmisi impul nyeri yang disebabkan oleh penusukan arteriovenous fistula.

Pemijatan pada titik LI-4 termasuk kategori stimulasi kutaneus. Stimulasi pada kutaneus sesuai digunakan untuk manajemen nyeri kanulasi arteriovenous fistula, karena secara teori nyeri kanulasi arteriovenous fistula termasuk pada nyeri akut yang dirasakan di area kuteneus. Berdasarkan ilmu akupunktur, titik LI-4 juga merupakan titik meridian dominan yang digunakan untuk mengurangi rasa sakit pada bahu, lengan, leher serta skapula.

Berdasarkan hasil penerapan EBN ditemukan bahwa tidak terdapat perbedaan sensasi nyeri antara pasien lakilaki dan perempuan. Hal ini sejalan dengan penelitian yang dilakukan oleh (Kaza, 2014) bahwa tidak terdapat perbedaan nyeri antara pasien perempuan dan laki-laki pada penusukan arteriovenous fistula dengan nilai $p=0,143$. Temuan yang didapat selama pelaksanaan EBN perbedaan antara wanita dan laki-laki dalam sensasi nyeri adalah dalam bentuk ekspresi nyeri. Wanita lebih cendrung memiliki ekspresi yang histeris dan ekspresif ketika nyeri sedangkan lelaki cendrung lebih tenang ketika menghadapi nyeri. Berkles (1999) dalam (Kaza, 2014) juga menyatakan bahwa wanita memiliki ambang nyeri yang rendah dan wanita lebih cendrung mendeskripsikan nyeri secara berlebihan dibanding lelaki.

Hasil pelaksanaan EBN menunjukkan tidak terdapat perbedaan skala nyeri pada pasien berdasarkan lama menjalani dialisis. Lama menjalani hemodialisis lebih dikaitkan dengan adaptasi pasien terhadap pengalaman nyeri selama 
menjalani hemodialisis. Setiap pasien akan mencoba beradaptasi terhadap nyeri yang dirasakannya. Pasien yang tidak mampu beradaptasi terhadap nyeri, maka ketika penusukan arteriovenous fistula pasien akan memandang sebagai suatu kecemasan dan ketakutan. Sebaliknya pada pasien yang memiliki adaptasi baik sudah memiliki koping dalam menghadapi penusukan arteriovenous fistula sehingga persepsi nyeri dirasakan tidak begitu besar. Menurut penelitian (Da Silva, Rigon, Corradi Dalazen, Bissoloti, \& Rabelo-Silva, 2016) pasien yang menjalani hemodialisis kurang dari 5 tahun memiliki nyeri yang lebih tinggi dari pada pasien yang menjalani hemodialisis lebih dari 5 tahun. Pada hasil pelaksanaan EBN, tidak ditemukan pengaruh lama menjalani hemodialisis terhadap nyeri kanulasi arteriovenous fistula karena pasien yang diambil menjadi sampel rata-rata memiliki skala nyeri sedang.

Berdasarkan umur, diketahui bahwa tidak terdapat perbedaan skala nyeri antara usia muda dan tua. Rentang umur pasien dalam penerapan EBN adalah 33 - 73 tahun. Pada pasien ditemukan bahwa masingmasing memiliki rentang nyeri dengan skala sedang dalam penusukan arteriovenous fistula. Usia dewasa cendrung lebih mampu beradapatasi dengan nyeri. Pada usia tua sebenarnya juga terdapat peningkatan nyeri terutama terkait dengan perubahan fisik pada usia tua. Penurunan masa lemak sub kutan mempengaruhi tingkatan nyeri saat kanulasi. Pada usia tua lebih terjadi penurunan masa lemak sub kutan, sehingga pasien tua cendrung lebih nyeri ketika dilakukan kanulasi.

Pengamatan selama melakukan EBN juga menemukan bahwa skala nyeri pasien lebih tinggi apabila penusukan dilakukan di lubang baru. Pada pasien yang penusukan dilakukan pada lubang yang lama, nyeri dirasakan lebih rendah. Penusukan di lubang lama saat kanulasi arteriovenous fistula disebut dengan metode button hole. Metode button hole atau lubang kancing diartikan sebagai cara penusukan arteriovenous fistula tepat pada satu titik yang menetap setiap menjalani hemodialisis, pada metode ini akan terbentuk jalur yang menetap (G. Silva et al., 2010). Hasil penelitian G. Silva et al. (2010) menunjukkan bahwa sensasi nyeri lebih rendah dirasakan pada pasien yang mendapatkan penusukan arteriovenous fistula dengan metode button hole dibandingkan metode ladder. Sensasi nyeri pada metode ladder lebih tinggi dibandingkan metode button hole karena pada metode ladder penusukan dilakukan menggunakan beberapa titik yang berbeda sebagai tempat insersi jarum pada setiap hemodialisis. Penusukan jarum pada tempat yang berbeda setiap kali hemodialisis menyebabkan kerusakan jaringan kulit berulang di tempat yang berbeda sehingga menimbulkan sensasi nyeri yang lebih tinggi pada pasien.

\section{Simpulan}

Hasil penerapan EBN ini terbukti efektif dapat mengurangi nyeri pasien saat dilakukan penusukan arteriovenous fistula sehingga intervensi pemijatan titik LI-4 dapat diterapkan sebagai salah satu intervensi keperawatan manajemen nyeri non farmakologis untuk mengurangi nyeri penusukan arteriovenous fistula. Pemijatan pada titik LI-4 dapat memperkaya intervensi mandiri keperawatan sehingga dapat dikembangkan dalam pembelajaran praktik mahasiswa.

\section{Ucapan Terima Kasih}

Ucapan terima kasih diucapkan kepada Direktur RSUP Fatmawati Jakarta, Kepala Ruangan dan perawat ruangan hemodialisis, pasien yang telah bersedia menjadi responden serta pihak terkait yang telah memberikan dukungan dan 
bantuan dalam proses pelaksanaan EBN ini.

\section{Referensi}

da Silva, O. M., Rigon, E., Corradi Dalazen, J. V., Bissoloti, A., \& Rabelo-Silva, E. R. (2016). Pain during Arteriovenous Fistula Cannulation in Chronic Renal Patients on Hemodialysis. Open Journal of Nursing, 6(12), 10281037.

https://doi.org/10.4236/ojn.2016.612 098

Fareed, M., El-Hay, A., \& El-Shikh, A. (2014). Cutaneous Stimulation: its Effect on pain Relieving among Hemodialysis Patients. Journal of Education and Practice, 5(1), 9-20.

Jha, V., Garcia-Garcia, G., Iseki, K., Li, Z., Naicker, S., Plattner, B., ... Yang, C. W. (2013). Chronic kidney disease: Global dimension and perspectives. The Lancet, 382(9888), 260-272.

https://doi.org/10.1016/S01406736(13)60687-X

Kaza, B. N. K. (2014). Pain during Arterio-Venous Fistula (AVF) Cannulation. American Journal of Internal Medicine, 2(5), 87-89. https://doi.org/10.11648/j.ajim.20140 205.12

Kementrian Kesehatan Ri. (2013). Riset kesehatan dasar. Jakarta : Balitbang Kemenkes RI

Mirtajadini, H., Kalroozi, F., \& Pishgooie, A. (2016). Shiatsu massage and the pain intensity of venipuncture in patients undergoing hemodialysis. Miliatary Caring Science, 3(1), 2734.

Silva, G., Silva, R. A. da, Nicolino, A. M., Pavanetti, L. C., Alasmar, V. L., Guzzardi, R., ... Araújo, I. de M. (2010). Initial experience with the buttonhole technique in a Brazilian hemodialysis center. Jornal
Brasileiro de Nefrologia: 'orgão Oficial de Sociedades Brasileira E Latino-Americana de Nefrologia, 32(3), 257-62. Retrieved from http://www.ncbi.nlm.nih.gov/pubmed $/ 21103688$

Sukandar, Enday. (2013). Nefrologi Klinik. Pusat Informasi Ilmiah : Bandung

Ziba, F. N., Soltanpoor, F., \& Mohammadi, N. (2013). Effect of huko point ice massage on pain degree during arteriovenous fistula puncture in hemodialysis patients. Regional Anesthesia and Pain Medicine, 4(2), 25-34. Retrieved from

http://resolver.library.ualberta.ca/reso lver?sid=OVID: embase\&id=pmid:\&i d=doi:\&issn=1098-

$7339 \&$ isbn $=\&$ volume $=38 \&$ issue $=4 \&$ spage $=\&$ pages $=\&$ date $=2013 \&$ title $=R$ egional+Anesthesia+and+Pain+Medi cine\&atitle $=$ Effect + of + huko+point $+\mathrm{i}$ ce+massage+on+pain+degree+during +arteriov 